\title{
Environment Knowledge, Law-Abiding Consciousness and Risk Perception Influencing Environmental Behavior
}

\author{
Zheng Lian ${ }^{1,3, *}$, Qianyanhui Qian ${ }^{2,1}$, Lejun Bao ${ }^{4}$ \\ ${ }^{1}$ School of Public Affairs, Zhejiang University, Hangzhou, 310058, China \\ ${ }^{2}$ School of Humanities and Management, Yunnan University of Chinese Medicine, Kunming, 650500, China \\ ${ }^{3}$ Department of Transport of Wenzhou, Wenzhou, 325000, China \\ ${ }^{4}$ Department of Finance of Wenzhou, Wenzhou, 325000, China
}

\begin{abstract}
This research investigates the impact of environmental knowledge, law-abiding consciousness, and risk perception on environmental behavior through structural equation modeling (SEM) analysis. The results found that: 1 . The higher the awareness of environmental knowledge, the higher the friendliness of environmental protection behavior. 2. The higher the awareness of risk perception, the higher the friendliness of environmental protection behavior. 3. The stronger the law-abiding consciousness, the higher the friendliness of environmental protection behavior. 4. Individual cognitive ability has a positive and significant impact on environmental knowledge, risk perception and law-abiding consciousness.
\end{abstract}

\section{Introduction}

Inglehart (1989), one of the founders of environmental protection theory, argues that environmental protection behavior is a manifestation of the improvement of quality of life and self-expression of values in the postmaterialist era. Environmental behavior arising is the result of nation development and their gradual emphasis on safety considerations. Only relatively recently, environmental protection has become an important consideration in human socio-economic development decisions. [1] For the study of environmental protection behavior issues, academic circles have carried out discussions in many fields such as ecology, economics, sociology, behavioral science, etc. The important causal variables of environmental behavior lie in different subject areas. Although environmental protection has become a major concern of humankind, ecological problems have provided a lot of terrible news to society indefinitely. A large number of studies can prove that the environmental damage caused by human behavior themselves is the root cause of environmental protection. Therefore, this article makes empirical research on three influencing factors of environmental protection behavior based on the Chinese General Social Survey (CGSS 2010) database, respectively, environmental knowledge, law-abiding consciousness and risk perception.

\section{Literature Review and Hypothesis}

Human beings are stepping into an environmental world, and everyone who considers himself a realist will be forced to adjust his behavior according to the impact of environmental protection. [2] The early research definition of environmental behavior considered it to be a single dimension. Lately, Paul C. Stern et al. classified environmental protection behavior into environmental activism, nonactivist behaviors in the public sphere, private-sphere environmentalism and other environmentally significant behavior. As far as the characteristics and trends of citizens' environmental behaviors are concerned, the development level of Chinese citizens in private environmental behavior is higher than that of public environmental behavior, which means environmental behavior in private-sphere would have significant impact on environmental protection. [3] This research mainly focuses on environmental protection behaviors in the private sphere and take individuals or families as the study unit. The green life and consumption behavior belong to this category, such as using clean energy in daily life, recycling items, sorting waste, purchasing green food, and using environmentally friendly energy-saving appliances.

The public's intention to respond to environmental protection is quite complicated, and environmental awareness is the basis for supporting environmentally friendly or hostile manners. [4] In the 1990 of Orange County, California annual survey, residents who believed that environmental issues pose a serious threat to their health and well-being were more likely to participate fully in environmental practices, such as those who assessed air and water pollution as a serious threat might reduce driving. [5] Uncertain environmental problems may make people's risk perception and general cognitive tendencies significantly related to environmental protection behaviors. Risk perception helps people to adopt friendly environmental behavior.

\footnotetext{
* Corresponding author: lianzheng@zju.edu.cn
} 
Ajzen' theory of planned behavior, assuming that people are motivated to avoid punishment and seek rewards. According to this TPB model, the decision is made by a reasonable assessment of the consequences of the behavior. Social norms are an important influencing factor in the theoretical framework of TPB. Social norms are mainly conceptualized as perceivable social environmental pressures, which is people's expectation judgments on performing or not. [6] Consistent with the above point of view, the legal approach has always been used as a tool for regulating social normative behavior. People's concept of law compliance can be reflected in accepting the behavioral constraints stipulated by the law, thereby stimulating the consciousness of obeying the law. [7] The increased awareness of law compliance is conducive to environmental protection.

As the relationship between the living environment and the individual's survival becomes closer, people's indepth knowing of environmental knowledge will affect individuals' environmental protection behavior. Attitudebehavior theory points out that attitudes are significant to individual behavior. Positive environmental attitudes are the influencing factors of public participation in environmental protection, and attention to issues is ahead of positive attitudes. Another factor affecting the three facets is the individual's cognitive ability. The improvement of personal cognitive abilities, especially language cognition, helps to enhance risk cognition, legal awareness and attention to environmental issues. Therefore, the improvement of individual cognitive abilities may have an indirect impact on environmental protection behavior. In addition, univariate variables have limitations for influencing behavior changes. Behavior is determined by multiple variables, and sometimes there are interactions between different variables. [8] Based on the above research foundations, this study proposes the following hypotheses:
H1 The higher the attention of environmental knowledge, the higher the friendliness of environmental protection behavior.

H2 The higher the awareness of risk perception, the higher the friendliness of environmental protection behavior.

H3 The higher the law-abiding consciousness, the higher the friendliness of environmental protection behavior.

H4 Individual cognitive ability has a positive and significant impact on the factors of environmental knowledge attention, risk perception, and law-abiding consciousness.

\section{Research Design}

\subsection{Data Preparation}

The data used in this research comes from the Chinese General Social Survey 2010 database (CGSS 2010) of Renmin University of China. The survey uses multistage sampling across whole country, with a total of 100 selected county-level units plus 5 metropolises, 480 villages/neighborhoods, and 12,000 individuals. According to research needs, this research cleans the database samples, removes missing numbers, and finally obtains a total of 2960 samples.

\subsection{Variable Declaration}

Find out the survey questions related to the research hypothesis from the CGSS 2010 questionnaire, corresponding to 4 variables with a total of 18 questions. Each question uses a Likert scale to measure latent variables. Table 1. summarizes variables' operational definition and questions.

Table 1. Variables' operational definition and questions

\begin{tabular}{|c|c|c|}
\hline Variables & Operational Definition & Questions \\
\hline $\begin{array}{l}\text { Environmental } \\
\text { Behavior }\end{array}$ & $\begin{array}{l}\text { General term for activities that } \\
\text { directly and indirectly affect } \\
\text { the environment }\end{array}$ & $\begin{array}{l}\text { I20A. Do you often sort glass, aluminum cans, plastic, or newspapers for } \\
\text { recycling? } \\
\text { I20B. Do you often deliberately buy fruits and vegetables without fertilizers } \\
\text { and pesticides? } \\
\text { I20D. Do you often deliberately reduce the consumption of oil, gas, } \\
\text { electricity and other energy or fuels at home to protect the environment? } \\
\text { I20E. Do you often conserve water or reuse it for environmental protection? } \\
\text { I20F. Do you often deliberately not buy certain products for the sake of } \\
\text { environmental protection? }\end{array}$ \\
\hline $\begin{array}{l}\text { Environmental } \\
\text { Knowledge }\end{array}$ & $\begin{array}{l}\text { Awareness and concern about } \\
\text { environmental issues }\end{array}$ & $\begin{array}{l}\text { I6A. How much do you care about environmental issues. } \\
\text { I8B. How much do you know about the causes of the various environmental } \\
\text { problem? }\end{array}$ \\
\hline $\begin{array}{l}\text { Law-Abiding } \\
\text { Consciousness }\end{array}$ & $\begin{array}{l}\text { The extent to which people } \\
\text { comply with the law }\end{array}$ & $\begin{array}{l}\text { I8A. How much do you know about the solutions to the above problems. } \\
\text { D221. What is the degree of occurrence of your following behavior- } \\
\text { compliance with traffic rules. } \\
\text { D222. What is the extent of your following behavior-compliance with work- } \\
\text { related regulations. } \\
\text { D223. What is the extent of your following behavior-compliance with } \\
\text { government or departments' regulations. } \\
\text { D225. What is the extent of your following behavior-buying fake counterfeit } \\
\text { products. }\end{array}$ \\
\hline Risk & Ability to sense and respond to & I2503. Humans often have disastrous consequences for natural destruction. \\
\hline
\end{tabular}




\begin{tabular}{|c|c|c|}
\hline Perception & $\begin{array}{l}\text { emergencies or difficult } \\
\text { occasions }\end{array}$ & $\begin{array}{l}\text { I2505. Humans are currently abusing and destroying the environment. } \\
\text { I2506. If everything continues as it is, we will soon suffered severe from } \\
\text { environmental disasters. }\end{array}$ \\
\hline $\begin{array}{l}\text { Individual } \\
\text { Cognitive } \\
\text { Ability }\end{array}$ & $\begin{array}{l}\text { The ability of understanding } \\
\text { information, specifically } \\
\text { language ability }\end{array}$ & $\begin{array}{l}\text { A50. What do you think of your ability to speak Mandarin? } \\
\text { A51. What standard do you think you have the ability to understand } \\
\text { English? } \\
\text { A52. What do you think of your ability to speak English? }\end{array}$ \\
\hline
\end{tabular}

\subsection{Validity Test}

When conducting SEM, researchers often first evaluate the measurement model (whether the measured variables accurately reflect the desired constructs or factors) before assessing the structural model.

Table 2. Convergence validity

\begin{tabular}{|c|c|c|c|c|c|c|c|c|c|}
\hline & & Unstd. & S.E. & t-value & $\mathbf{P}$ & Std. & SMC & CR & AVE \\
\hline $\mathrm{I} 20 \mathrm{~A}$ & EB & 1.000 & & & & .498 & .248 & .764 & .408 \\
\hline I20B & EB & .672 & .042 & 15.914 & $* * *$ & .373 & .139 & & \\
\hline I20D & EB & 1.064 & .044 & 24.114 & $* * *$ & .757 & .573 & & \\
\hline $\mathrm{I} 20 \mathrm{E}$ & EB & 1.061 & .044 & 24.039 & $* * *$ & .749 & .561 & & \\
\hline $\mathrm{I} 20 \mathrm{~F}$ & EB & .978 & .041 & 23.706 & $* * *$ & .720 & .518 & & \\
\hline I6A & EK & 1.000 & & & & .335 & .112 & .703 & .472 \\
\hline I8B & EK & 2.234 & .137 & 16.361 & $* * *$ & .701 & .491 & & \\
\hline I8A & EK & 3.145 & .236 & 13.351 & $* * *$ & .901 & .812 & & \\
\hline A 50 & $\mathrm{RP}$ & 1.000 & & & & .437 & .191 & .850 & .675 \\
\hline A51 & $\mathrm{RP}$ & 1.578 & .063 & 25.104 & $* * *$ & .953 & .908 & & \\
\hline A52 & $\mathrm{RP}$ & 1.480 & .059 & 24.944 & $* * *$ & .962 & .925 & & \\
\hline D221 & LA & 1.000 & & & & .717 & .514 & .825 & .546 \\
\hline D222 & LA & 1.117 & .038 & 29.277 & $* * *$ & .593 & .352 & & \\
\hline D223 & LA & 1.130 & .029 & 38.887 & $* * *$ & .853 & .728 & & \\
\hline D225 & LA & .930 & .025 & 37.055 & $* * *$ & .767 & .588 & & \\
\hline I 2503 & $\mathrm{RP}$ & 1.000 & & & & .593 & .352 & .474 & .244 \\
\hline I 2505 & $\mathrm{RP}$ & .969 & .123 & 7.864 & $* * *$ & .539 & .291 & & \\
\hline I2506 & $\mathrm{RP}$ & .507 & .060 & 8.461 & $* * *$ & .299 & .089 & & \\
\hline A50 & ICB & 1.000 & & & & .437 & .191 & .850 & .675 \\
\hline A51 & ICB & 1.578 & .063 & 25.104 & $* * *$ & .953 & .908 & & \\
\hline A52 & ICB & 1.480 & .059 & 24.944 & $* * *$ & .962 & .925 & & \\
\hline
\end{tabular}

Table 3. Discriminant validity

\begin{tabular}{ccccccc}
\hline & AVE & RP & LA & EK & ICA & EB \\
\hline RP & .244 & $\mathbf{. 4 9 4}$ & & & & \\
LA & .546 & .159 & $\mathbf{. 7 3 9}$ & & & \\
EK & .472 & .342 & .106 & $\mathbf{. 6 8 7}$ & & \\
ICA & .675 & .258 & .052 & .316 & $\mathbf{. 8 2 2}$ & \\
EB & .408 & .392 & .188 & .356 & .204 & $\mathbf{. 6 3 9}$ \\
\hline
\end{tabular}

This study performs a CFA analysis on all facets. The composite reliability (CR) value is the combination of the reliability of all measured variables, which indicates the internal consistency of the variable index, which is equivalent to cronbach's alpha. Above 0.7 is an acceptable threshold. A higher CR value indicates a higher internal consistency of the variable. [9] AVE calculates the average of the explanatory level of the latent variable to the measured variable, which is generally greater than 0.5 . A higher AVE indicates that the variable has higher convergence validity. Except that the $\mathrm{CR}$ value of the risk perception is slightly lower, the other variables have convergence validity. Square root of AVE in bold on diagonals. Off diagonals are Pearson correlation of constructs. It can be seen from the table in Table 2 that the discriminant validity meets the conditions.

\subsection{Research Model}

Finally, IBM SPSS Amos 23 is used to adjust the latent variables that do not meet the above conditions, and the structural equation model of Figure 1 is obtained after modifying the model. 


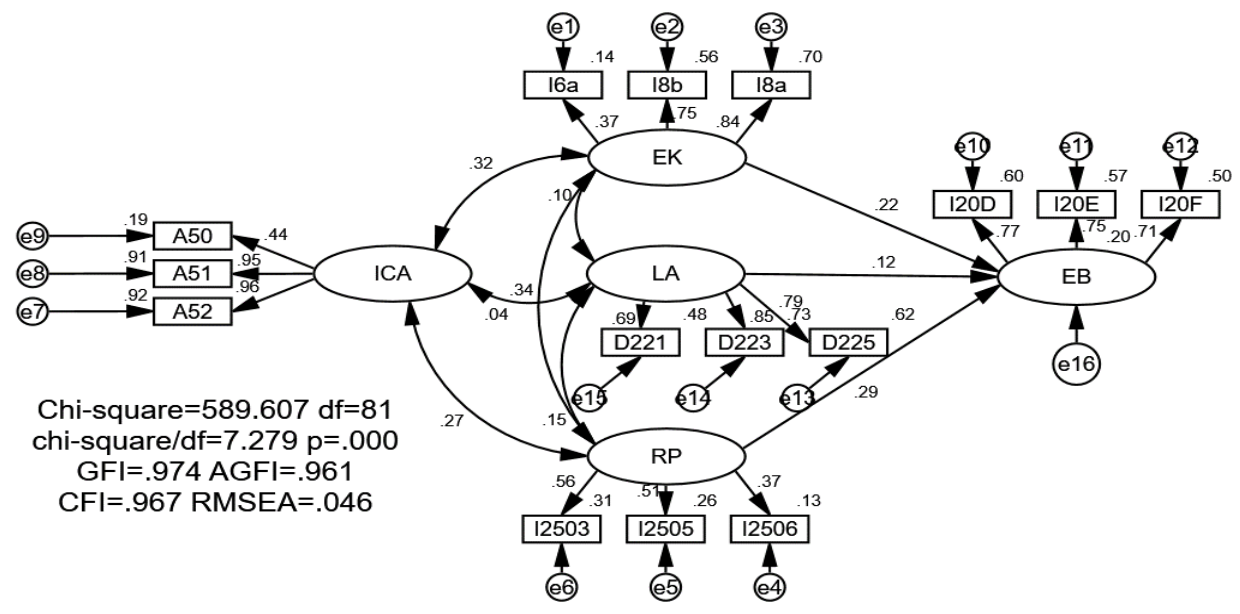

Fig. 1. Research model

\section{Conclusion}

The $\mathrm{P}$ value in the table of non-standardized coefficients significantly indicates that the hypothesis holds, the independent variable changes by one unit, and the dependent variable changes the corresponding unit. The normalized coefficients indicate that one standard deviation of the independent variable changes, and the standard deviation of the variable changes correspondingly. The hypotheses of this study are all valid. The higher the degree of attention to environmental knowledge, the higher the friendliness of environmental protection behavior; the stronger the awareness of risk perception, the higher the friendliness of environmental protection behavior; individual cognitive ability has a significant effect on other independent variables.

Table 4. Regression weights

\begin{tabular}{ccccccc}
\hline & & & Estimate & C.R. & P & Results \\
\hline EB & $<---$ & EK & 0.438 & 7.795 & $* * *$ & support \\
EB & $<---$ & LA & 0.181 & 5.31 & $* * *$ & support \\
EB & $<---$ & RP & 0.522 & 7.757 & $* * *$ & support \\
I6A & $<---$ & EK & 1 & & & \\
I8B & $<---$ & EK & 2.151 & 17.6 & $* * *$ & support \\
I8A & $<---$ & EK & 2.646 & 17.18 & $* * *$ & support \\
I2506 & $<---$ & RP & 1 & & & \\
I2505 & $<---$ & RP & 1.491 & 11.669 & $* * *$ & support \\
I2503 & $<---$ & RP & 1.515 & 11.683 & $* * *$ & support \\
A52 & $<---$ & ICA & 1 & & & \\
A51 & $<---$ & ICA & 1.069 & 64.745 & $* * *$ & support \\
A50 & $<---$ & ICA & 0.68 & 25.31 & $* * *$ & support \\
I20D & $<---$ & EB & 1 & & & \\
I20E & $<---$ & EB & 0.98 & 33.589 & $* * *$ & support \\
I20F & $<---$ & EB & 0.886 & 32.794 & $* * *$ & support \\
D225 & $<---$ & LA & 1 & & & \\
D223 & $<---$ & LA & 1.185 & 38.321 & $* * *$ & support \\
D221 & $<---$ & LA & 1.015 & 35.763 & $* * *$ & support \\
\hline
\end{tabular}

\section{References}

1. Inglehart $\mathrm{R}$, The Culture Shift in Advanced Industrial Society (Princeton University Press, NG, 1989)

2. Bleek F.S, Wieviel Umwelt braucht der Mensch (Tsinghua University Press, BJ, 2003)

3. Wang L, Zhong Y, Research on Environmental Attitudes, Behavior Categories and Factors of Chinese Urban Residents. JSJU 22,6(2014)

4. Dunlap R.E, Scarce R, Poll Trends: Environmental Problems and Protection, POQ 4,55(1991)

5. Baldassare M, Katz C, The Personal Threat of Environmental Problems as Predictor of Environmental Practices, EB 24,5(1992)

6. Icek A, The theory of planned behavior, OBHDP, 2,50(1991)

7. Zhou K, Analysis of China's Ecological Environment Legal System, JRUC, 6(2000)

8. Hansmann R, Bernasconi P, Justifications and selforganization as determinants of recycling behavior: The case of used batteries, RCR, 47,2(2006)

9. Fornell C, Larcker D.F, Evaluating Structural Equation Models with Unobservable Variables and Measurement Error, JMR, 19,1(1981) 